\title{
Do Interpersonal Networks Mediate the Relationship Between International Academic Mobility and Entrepreneurial Knowledge?
}

\author{
Kevin De Moortel ${ }^{1} \mathbb{D} \cdot$ Thomas Crispeels $^{1} \cdot$ Jinyu Xie $^{2} \cdot$ Qiaosong Jing $^{2}$
}

Accepted: 9 June 2021 / Published online: 5 August 2021

(C) The Author(s) 2021

\begin{abstract}
Temporary international mobility is an increasingly relevant practice amongst academics. However, current literature lacks understanding on whether such mobility influences the individual academics' entrepreneurial knowledge. This paper hypothesizes that temporary international academic mobility is conducive to the academic's entrepreneurial knowledge and that interpersonal social networks play a crucial role in the transfer of this knowledge through their strength and size properties. We perform a Partial Least Squares - Structural Equation Model and build upon an original survey data set collected amongst 281 Chinese academics. We find that the size of one's interpersonal social network fully mediates the relationship between international academic mobility and entrepreneurial knowledge. This result points to the importance of a structurally broad - rather than a relationally strong - international social network in the academic's accumulation of entrepreneurial knowledge abroad.
\end{abstract}

\footnotetext{
Supplementary Information The online version contains supplementary material available at https://doi.org/10.1007/s11024-021-09448-3.

Kevin De Moortel

kevin.de.moortel@vub.be

Thomas Crispeels

thomas.crispeels@vub.be

Jinyu Xie

lesan0312@hotmail.com

Qiaosong Jing

515108143@qq.com

1 Department of Business Technology \& Operations, Vrije Universiteit Brussel, 1050 Brussel, Belgium

2 Business School, Sichuan University, Chengdu 610064, China
} 
Keywords International academic mobility $\cdot$ Knowledge-based view · Interpersonal networks · Entrepreneurial knowledge

JEL Classification $\quad$ D $8 \cdot$ F $29 \cdot$ I 23

\section{Introduction}

Internationalization is inherent to higher education in the 21st century (Baruffaldi and Landoni 2012; Audretsch et al. 2015). Since the 1990s, academics increasingly move across international borders for different durations and reasons (Rostan and Höhle 2014; Teichler 2015). Many countries have developed policies and programs to support international mobility by students and faculty (Scellato et al. 2015). For example, in Europe, the Erasmus Program and the European Research Area increase the opportunity for academics to be internationally mobile (Maggioni and Uberti 2009). The United States has its long-established J and H visas for short-term academic exchanges (Wang et al. 2019). The China Scholarship Council (CSC) and Horizon 2020 projects provide financial assistance to Chinese academics who wish to study abroad (De Moortel and Crispeels 2018). The idea behind these mobility programs is that the accumulation of networks and collaborations abroad enhances the academic's individual capabilities, productivity and career development, and that these benefits extend to a regional or country level in terms of increased welfare through overall knowledge exchanges and enlargement of the regional or national knowledge stock (Bauder 2020; Veugelers and Van Bouwel 2015; Regets 2007).

Consequently, a scholarly debate emerged about the impact of international mobility on academics (Teichler 2015). For example, when it comes to international student mobility, we expect increases in international competences or in comparative reasoning, and, when it comes to staff mobility, increases in scientific output (e.g. publications, citations, or patents) or academic quality. This debate has resulted in a number of scholars (e.g. Wang et al. 2019; Yasuda 2016; Krabel et al. 2012; Edler et al. 2011; Cañibano et al. 2011; Stephan and Levin 2001), although using different operationalizations and conceptualizations, who study the relationship between international academic mobility and knowledge transfer. ${ }^{1}$ Within this debate, we aim to untangle the relationship between international academic mobility and academic entrepreneurship further. Academic entrepreneurship refers to the efforts undertaken by an academic to commercialize an invention, including patenting and licensing, and the creation of a start-up company (Siegel and Wright 2015). These efforts constitute the more formal knowledge transfer activities. In their work, Siegel and Wright (2015) note that mobility is increasingly considered a way to foster academic entrepreneurship, next to the existence of technology transfer offices

\footnotetext{
1 We refer to knowledge transfer as the range of activities in which academics are involved to transfer knowledge and technologies into society. These activities range from informal ones (e.g. informal meetings, personal exchanges, and trainings) to more formal ones (e.g. licensing, spin-off creation, and contract research) (Perkmann et al. 2013).
} 
and science parks. This notion draws on the assumption that knowledge and/or interpersonal networks gained through international mobility are conducive to the academics' engagement in the entrepreneurial activities (Krabel et al. 2012). However, to the best of our knowledge, no study has actually tested this strong assumption.

To address this gap, we study the relationship between international mobility and entrepreneurial knowledge from the individual academic perspective. We choose to focus on temporary international mobility, which holds the academic's intention to return to the home country. Temporary international mobility is an increasingly relevant phenomenon in academia, especially amongst $\mathrm{PhD}$ students and post-docs (Teichler 2015; Edler et al. 2011), while permanent mobility of academics is rather limited in practice (Cervantes and Guellec 2002). Our premise is that international temporary academic mobility is conducive to the academic's entrepreneurial knowledge and that interpersonal social networks mediate the relationship. In doing so, we add insights to the impact of international temporary mobility and interpersonal social networks on the accumulation of entrepreneurial knowledge of academics (Cañibano et al. 2008); an outcome which is often explicitly or implicitly assumed.

Our study provides support to the idea that academics reap benefits from their internationalization efforts, adhering to the brain gain discourse. We also increase our understanding on the relationship between of international mobility and academic entrepreneurship, as different authors use different operationalizations without further clarification. It is striking to see how, although international academic mobility has been emphasized for several decades, our understanding on the phenomenon and its impact remains scattered, underdeveloped and mis-aligned (Veugelers and Van Bouwel 2015; Teichler 2015).

\section{Literature Review and Hypotheses Development}

\section{International Temporary Academic Mobility}

Academic mobility refers to physical - as opposed to virtual - movements of students and faculty across borders (Rostan and Höhle 2014). Geographically, academics can move across national borders, i.e. international academic mobility, and be mobile domestically, i.e. domestic academic mobility. When it comes to studying the impact of international academic mobility on knowledge transfer or academic entrepreneurship, we agree with the view of Edler et al. (2011) that one should differentiate between temporary and permanent movements of academics. While temporary mobility refers to academics going abroad to gain experiences and come back to the home country, permanent mobility does not hold the particular intention to come back. Such distinction is crucial to debates on brain drain and brain gain. While brain drain refers to international mobility negatively affecting the academic's home country, e.g. through decreases of technological capabilities or overall competitiveness (Adams 1968), brain gain puts emphasis on resulting benefits for the home country, e.g. increases in welfare through overall knowledge exchanges and better career development of individual academics (Regets 2007). 
Literature on permanent mobility mainly devotes attention to the (return) migration of academics (e.g. Wang et al. 2019; Gibson and McKenzie 2014). Davenport (2004) and Trippl (2013) provide support to the idea that internationally mobile academics return home with cutting-edge knowledge and networks and act as important transmitters of technology and tacit knowledge. Other scholars (e.g. Krabel et al. 2012; Stephan and Levin 2001) find that entrepreneurial exploitation, operationalized as nascent entrepreneurship or the creation of spinoff companies, is stimulated when the academic is foreign born or educated. Similarly, scholars find a positive impact on entrepreneurial opportunity identification through academic patenting or find a trend in the inventive activities of foreignborn academics (e.g. Hunt and Gauthier-Loiselle 2010; Wadhwa et al. 2008). Jonkers and Tijssen (2008) and Jonkers and Cruz-Castro (2013) find a positive impact of permanent international mobility on academic publications.

Temporary international academic mobility is an increasingly relevant yet often underestimated phenomenon (Teichler 2015). The Changing Academic Profession (CAP) survey, for example, concluded that one third of all academics surveyed engaged in some sort of temporary international mobility. The distinction between the different types of temporary mobility is subtle and debatable, especially when it comes to defining the duration of the activities (Table 1). Arguably, such definition is arbitrary anyway (Cañibano et al. 2011). For example, an academic might be participating to workshops and conferences while on a research stay abroad or a particular teaching activity abroad can take only a few days, several weeks, or can happen on a recurrent basis. In such cases, it becomes very hard to assess the impact of (isolated) experiences on one's knowledge or networks gained.

Despite the unclear boundaries, scholars have started to see value in the role of non-permanent movements of academics in knowledge transfer and networking activities (Cañibano et al. 2011; Edler et al. 2011). Different temporary international mobility experiences shape one's knowledge and networks differently. For example, Teichler (2015) notes that there is a distinction between students who study abroad for only a semester and those who participate to a full study program abroad, since the former imposes contrasting learning environments at different universities impacting one's knowledge differently. Similarly, short-term international experiences may impact knowledge transfer activities differently and play a different role in the development of international connections (Edler et al. 2011; Melkers and Kiopa 2010). Melkers and Kiopa (2010), for example, indicate that short-term visits are especially useful in the consolidation and maintenance of international networks. Edler et al. (2011), who focus on intra-sectoral research mobility, find that temporary international mobility is conducive to the academic's overall collaborations with industry.

International temporary academic mobility thus comprises a range of interand intra-sectoral experiences: university, industry, or governmental visits, participation in international conferences and workshops, research stays abroad, summer schools, international project meetings, contract research abroad, studies abroad and so forth. These experiences range from short-term moves of a few days/weeks to longer movements over one year and form by no means a coherent 
Table 1 International academic mobility: an overview of (some) distinctions made

\begin{tabular}{|c|c|c|c|c|}
\hline & \multicolumn{3}{|c|}{ Temporary Mobility } & Permanent Mobility \\
\hline Definition & \multicolumn{3}{|c|}{$\begin{array}{l}\text { Mobility with the intent to return to the home } \\
\text { country }\end{array}$} & $\begin{array}{l}\text { Mobility with the intent } \\
\text { to stay in the host } \\
\text { country }\end{array}$ \\
\hline $\begin{array}{l}\text { Associated } \\
\text { terminology }\end{array}$ & $\begin{array}{l}\text { Recurrent or cir } \\
\text { mobility }\end{array}$ & ulatory & $\begin{array}{l}\text { Job or } \\
\text { education } \\
\text { mobility }\end{array}$ & $\begin{array}{l}\text { (Return) Migration, } \\
\text { skilled migration }\end{array}$ \\
\hline Duration & Short-term & Middle-term & $\begin{array}{l}\text { Long-term or } \\
\text { indefinite }\end{array}$ & Indefinite \\
\hline $\begin{array}{l}\text { Activities/ } \\
\text { Experiences }\end{array}$ & $\begin{array}{l}\text { Conferences, } \\
\text { workshops, } \\
\text { teaching, } \\
\text { (in)formal } \\
\text { short visits }\end{array}$ & $\begin{array}{l}\text { Summer } \\
\text { schools, } \\
\text { research } \\
\text { stays, } \\
\text { contract } \\
\text { research, } \\
\text { temporary } \\
\text { study (e.g. } \\
\text { semester), } \\
\text { internships }\end{array}$ & $\begin{array}{l}\text { Work contracts } \\
\text { (employment } \\
\text { abroad), } \\
\text { foreign } \\
\text { doctoral } \\
\text { training, study } \\
\text { of full } \\
\text { programs }\end{array}$ & $\begin{array}{l}\text { Migration for study or } \\
\text { work }\end{array}$ \\
\hline $\begin{array}{l}\text { Exemplary } \\
\text { literature }\end{array}$ & $\begin{array}{l}\text { Cañibano et al. } \\
(2008) ; \\
\text { Melkers and } \\
\text { Kiopa (2010) }\end{array}$ & $\begin{array}{l}\text { Edler et al. } \\
(2011) ; \\
\text { Pagani et al. } \\
\text { (2019); } \\
\text { Cañibano et } \\
\text { al. (2008, } \\
2011)\end{array}$ & Yasuda (2016) & $\begin{array}{l}\text { Wang et al. (2019); } \\
\text { Gibson and McKenzie } \\
\text { (2014); Davenport } \\
\text { (2004); Krabel et al. } \\
\text { (2012); Stephan and } \\
\text { Levin (2001) }\end{array}$ \\
\hline
\end{tabular}

Note: This overview does not include international academic mobility for non-professional or personal reasons (e.g. migration caused by a parental generation or temporary mobility not related to work/education)

bundle of activities. In this study, we choose to work with the full spectrum of temporary international mobility experiences.

\section{Entrepreneurial Knowledge}

To understand the relationship between international academic mobility and entrepreneurial knowledge, one should especially consider the perspective of the individual academic and the factors that drive the engagement in entrepreneurship (Goethner et al. 2012; Eckhardt and Shane 2003). Scholars acknowledge that, in entrepreneurship, knowledge is a key resource (Hayter 2016). In this respect, the knowledge-based view states that knowledge accumulation over time creates a knowledge base that allows someone to identify certain entrepreneurial opportunities (Venkataraman 1997; Alvarez and Busenitz 2001). People possess different knowledge bases which change over time as knowledge is accumulated through different life experiences (Shane 2002). Mobility is an integral part of the academic's life experiences.

Thus, for an entrepreneurial opportunity to be recognized, an academic needs insights which appear through the availability of accumulated knowledge within 
one's knowledge base (Jacobs 1969). Heterogeneity is identified as a key attribute to the development of such insights (Alvarez and Busenitz 2001). Especially the availability and increases of heterogeneous knowledge positively affects one's ability to recognize entrepreneurial opportunities since it allows academics to be more aware of potential uses, applications, and to assess commercial value (D'Este et al. 2012; Bercovitz and Feldman 2008; Alvarez and Busenitz 2001). Four knowledge categories are relevant in the accumulation of entrepreneurial knowledge. Market knowledge points to the need to understand markets, ways to serve markets, and customer problems (Shane 2002). Widding (2005) synthesizes the literature on the business knowledge needed to start a company and identifies three additional categories: product knowledge, organizational knowledge, and financial knowledge. Product knowledge refers to technological knowledge, production knowledge, and knowledge related to service offerings. Organizational knowledge refers to knowledge on (human resource) management and organizational structures. Finally, financial knowledge refers to knowledge on funding, financial management and taxes. We thus consider entrepreneurial knowledge as a compound construct of heterogeneous knowledge components on how to start and operate a business including know-how on opportunity identification or exploitation and on functional aspects of starting and running a business (Honig 2004; Pretorius et al. 2005).

This work poses that international temporary mobility positively contributes to one's entrepreneurial knowledge. Edler et al. (2011), for example, argue that the duration and frequency of international visits positively influence the academics' knowledge base. Academic mobility leads to a greater ability to find and develop rare or unique skill sets, which leads to cognitive integrations and the facilitation of opportunity identification (Olmos-Peñuela et al. 2015). Also, the exposure to specific and different country and/or institutional settings highly influences one's knowledge base (Busenitz et al. 2000). Indeed, internationally mobile academics are exposed to knowledge they did not have access to before (Edler et al. 2011). This leads these academics to hold a greater heterogeneity of ideas, perspectives, assumptions and creative techniques than those who did not have similar experiences before (McEvily and Zaheer 1999). Thus, through exposure to international experiences, academics accumulate external knowledge, including entrepreneurial knowledge, over time which augments their knowledge bases (Cañibano et al. 2008; Politis 2008). We hypothesize that:

Hypothesis 1 International temporary academic mobility positively influences the academic's entrepreneurial knowledge.

\section{The Mediating Role of Social Networks}

The role of social networks in international mobility has been recognized by many scholars (Cañibano et al. 2008). International mobility creates and shapes social networks (Scellato et al. 2015). At an interpersonal level, a social network is defined as a set of individuals and a set of linkages between these individuals (Brass 1992). Several macro-level concepts, like Mode 2, Triple Helix, 
and Post-Academic Science point to increased importance of social networks in academia (van Rijnsoever et al. 2008). Academics are involved in different network types, e.g. university networks (contacts within one's university), external university networks (contacts with other university researchers), and industrial networks (contacts with private companies). These networks may be of personal (e.g. friends or colleagues) or professional (e.g. mentors or business contacts) nature (Fernández-Pérez et al. 2015). Travels abroad allow for face-toface meetings and interactions (Urry 2002; Bienkowska et al. 2011) and bring along investments of effort, time and money, which result in international interpersonal relationships and networks (Bienkowska and Klofsten 2012; Orazbayev 2017). Through social networks, international mobility then influences individual knowledge (Cañibano et al. 2008). We model this causal relationship in Fig. 1. International temporary mobility causes changes in the academics' interpersonal network, which in turn causes changes in the academic's entrepreneurial knowledge (Wu and Zumbo 2008). We thus argue that one's interpersonal network explains the process of how temporary international mobility impacts entrepreneurial knowledge; providing a deeper understanding of the relationship (Baron and Kenny 1986). We investigate this impact through the strength and the size of interpersonal social networks, two properties that typically influence the transfer of information and knowledge (Fuentes-Fuentes et al. 2010). Network strength constitutes a relational property, while size represents a structural property (Phelps et al. 2012).

In terms of network strength, personal relations can be classified as either formal or informal according to the weak or strong tie that binds the individuals (Granovetter 1973). Weak ties provide access to new information by means of bridging disconnected individuals, while strong ties are more likely to provide redundant information. Still, some controversy exists on the effect of formal or informal networks on entrepreneurship and the usefulness of knowledge transferred. Cetin et al. (2016), for example, find that formal networks have a negative effect on entrepreneurship, while informal ones have a positive effect. Other studies (e.g. Davidsson and Honig 2003; Casson and Giusta 2007) show that formal networks also provide business opportunities and deliver valuable information. Additionally, literature notes that informal relations are useful to transfer tacit and heterogeneous knowledge and that formal networks help to transfer explicit and homogenous knowledge (Villanueva-Felez et al. 2013; Zaheer et al. 2010; Levin and Cross 2004). Taken together, these studies support the idea that social networks gained, in our case through international temporary mobility, positively contribute to one's entrepreneurial knowledge and that the strength of one's social network plays a role in determining the usefulness of the knowledge received. We thus hypothesize that:

Hypothesis 2a The relationship between the academic's temporary international mobility and entrepreneurial knowledge is mediated by one's interpersonal social network strength. 
In terms of network size, literature seems to agree on the fact that every relationship is able to provide information which turns into useful and meaningful knowledge when given context and interpretation by an individual (Chou 2005; Levin and Cross 2004; Granovetter 1973). From a knowledge-based view, academics receive and assimilate new knowledge through every network tie - whether formal or informal (van Rijnsoever et al. 2008; Hoang and Antoncic 2003; Rasmussen et al. 2015). Thus, international mobility increases the size of the academic's interpersonal network. The increase in network size extends one's knowledge base through the accumulation of multi-faceted heterogeneous entrepreneurial knowledge components (Edler et al. 2011) (Fig.1). We hypothesize that:

Hypothesis 2b The relationship between the academic's temporary international mobility and entrepreneurial knowledge is mediated by one's interpersonal social network size.

\section{Methodology and Data}

\section{Methodological Approach}

We perform a structural equation model (SEM) to test our hypotheses. A SEM has become a dominant analytical tool to test mediated models through the use of path analysis and latent variables (Hair et al. 2014). Path analysis is a form or multiple regression statistical analysis that allows to investigate patterns of effect within a model. Latent variables, which we will also refer to as constructs, are underlying variables that cannot be observed directly but consists of one of more observable indicators (Wong 2013). We use SmartPLS 3 software (Ringle et al. 2015) to run a Partial Least Squares (PLS) - SEM, which provides iterations to maximize the explained variance of endogenous constructs (Wold 1974).

\section{Research Context}

The Chinese setting is particularly relevant to our study. International mobility has intensified over the past years through supporting programs, such as the Ten Thousand Talents Program, Erasmus programs, China Scholarship Council grants, and Horizon 2020 projects (Wang et al. 2019). As such, Chinese universities increasingly collaborate on student or staff exchange programs and on joint PhDs. As an indication, the number of returned study abroad students and staff increased by $2179 \%$ in the period 2002-2015 (Li 2017). Talent pooling and training stimulates knowledge generation and knowledge transfer. International $\mathrm{PhD}$ programs or joint graduate schools allow for cross-country research and access to technologies that otherwise would have remained unattainable. These incentives reflect in the amount of university encouragement and support 


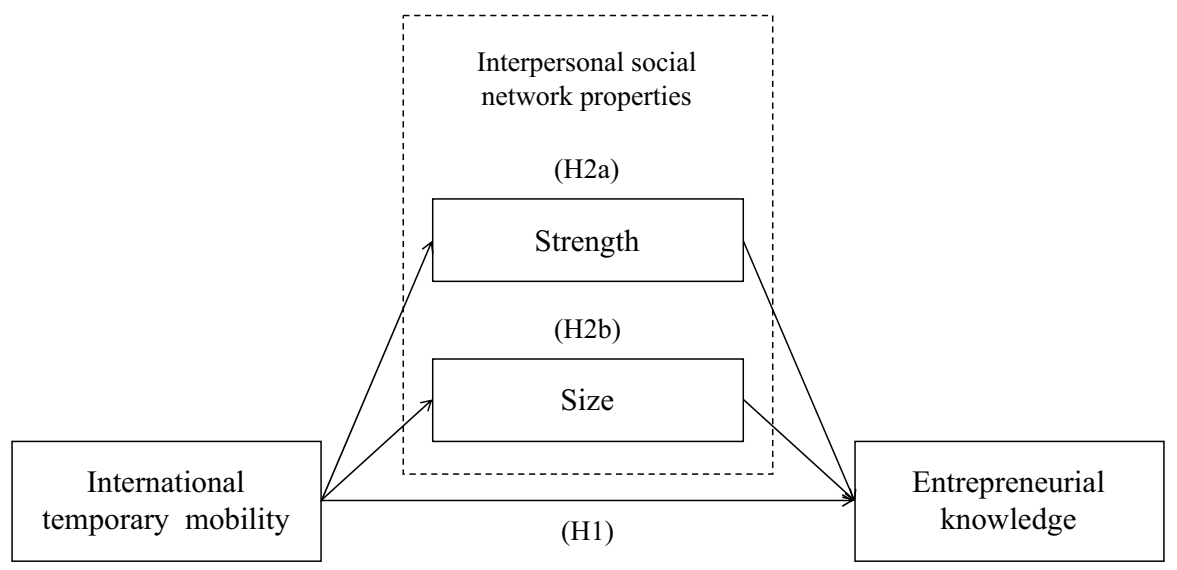

Fig. 1 Conceptual framework on international temporary mobility, interpersonal social networks, and entrepreneurial knowledge (source: authors)

Chinese academics perceive with regards to international mobility; $6.4 \%$ of the Chinese academics perceived no/low university encouragement and $13.3 \%$ indicated that no/little university support system was in place with regards to international mobility (own data).

Within Chinese society and culture, interpersonal networks play an important role. China embraces the concept of quanxi, the fundamental web of Chinese interpersonal relations, which is based on implicit mutual interest and benefit (Xin and Pearce 1996; Buckley et al. 2004). Xin and Pearce (1996) find that such relations even substitute more formal arrangements in a business context and that they are fertile ground for the transfer of inter-organizational knowledge. A specific stream of literature devotes attention to the role of guanxi in knowledge transfer (e.g. Davison et al. 2018; Ramasamy et al. 2006; Buckley et al. 2004). While such in-depth research is out of the scope of this study, we do note its importance with respect to the Chinese context and the mobility of Chinese academics as it characterizes our research sample as one that pays attention to the development of interpersonal networks.

\section{Data and Research Sample}

Although the internationalization of academia has received significant scholarly attention over the past decades, the quality and availability of data on international students and staff is worrisome (Teichler 2015). This is especially true for data on temporary mobility. EUROSTAT and the OECD, for example, recommended not to include student mobility shorter than one year. Teichler (2015) argues that surveys provide the most promising tool to increase our understanding on international mobility and its impact.

We launched an online survey amongst Chinese academics running from April till August 2019. The survey was translated using a double-translation design 
(English being the original language) and validated, linguistically and culturally, to fit the Chinese context. The survey was constructed and disseminated through Qualtrics Software (www.qualtrics.com). Academics were contacted through their publicly available email addresses which we retrieved from the websites of the Chinese Academy of Sciences (http://www.cas.cn/) and Daoshi ${ }^{2}$ (https://daoshi.eol.cn). We sent two reminders, with one week in-between mailings. Our survey was sent to 22,285 academics of which 1,981 (or 9\%) engaged in the survey. However, only 319 academics provided us with fully completed responses. We believe that this discrepancy is largely due to the survey set-up. The average completion time (12 minutes and 12 seconds) exceeded the recommended threshold of nine minutes and a considerable amount of questions was asked in matrix form. The combination of these two elements lowers completion rates drastically (www.qualitrics.com). In addition to this, the recent cybersecurity law in China (2016) may hamper the willingness of respondents to disclose personal data to Western platforms (Mei and Brown 2018). From the usable responses, we excluded 38 cases which did not report any international activities and/or did not have the Chinese nationality. In line with our operationalization of the international temporary academic mobility construct, we also excluded all cases that reported any permanent mobility activities. The above procedure leaves us with 281 usable responses and a sample error of $4.9 \%$ at the $90 \%$ confidence level $(Z=1.65, \mathrm{p}=\mathrm{q}=0.50) .^{3}$

As PLS-SEM is even capable to handle sample sizes smaller than 200, our sample is also sufficiently large to carry out any analyses (Hoyle 1995). Table 2 provides an overview of our sample characteristics. In terms of gender, the proportion of males is in line with the proportion reported in other survey studies (e.g. $63 \%$ in Shen (2008) and 54\% in Stanfield and Shimmi (2014)) and in line with Chinese academic staff population predominantly being male. ${ }^{4}$ In terms of the research area, our sample is mainly represented by academics from the natural sciences and technological disciplines (Morhman et al. 2011). This results from our survey partly being directed towards academics from universities which are part of the Chinese Academy of Sciences. Our sample tends to lean towards academics holding a professorship (74\%). In Shen's (2008) study, which covers a much larger sample, this proportion only represents $57 \%$. We decided to retain the responses of a variety of academic positions in order not to abide by the argument that professors are the only type of academics who accumulate entrepreneurial knowledge, engage in academic entrepreneurship, or move internationally (Siegel and Wright 2015). Pagani et al. (2019), for example, argue that students can have the same international experiences as faculty and may contribute to increases in knowledge stocks upon their return home. Our definition of the academic is thus broad.

\footnotetext{
${ }^{2}$ A Chinese platform commonly used amongst Chinese students to contact professors for the supervision of their master theses.

3 While the use of a $95 \%$ confidence level is more common, a $90 \%$ level is justified when the context of the study, which in our case is exploratory, the relevance of the findings, and alternative explanations are considered carefully (Cumming and Finch 2005; Cohen 1990).

4 Based on World Development Indicators from the World Bank (2020). Retrieved from https://data. worldbank.org/indicator/SE.TER.TCHR.FE.ZS?end=2018\&locations=CN. - CN\&start=1960.
} 


\section{Data Collection and Measures}

At the beginning of the survey, to reduce possible cognitive recollection problems and to assure accurateness and representativeness of the information provided, we asked respondents to take into account a five-year reference period. We provide an overview of our constructs of interest and how they were measured in the Appendix (electronic supplementary material).

\section{Independent and Mediating Constructs}

To capture temporary international mobility, we asked how frequently the respondents engaged in a range of international experiences. These experiences are: study, give lectures, official academic visit, summer school, internship, employment, contract research, consulting, research collaboration, attendance to conference or workshop, and laboratory or facility use. To take into account the full spectrum of temporary international mobility experiences, we did not opt for a single measure of international mobility as, for example, used in The GlobSci Survey (Scellato et al. 2015). Similar to Edler et al. (2011), McEvily and Zaheer (1999) and Fuentes-Fuentes et al. (2010), we captured the academic's network strength by a frequency measure, i.e. how frequently respondents communicated with their different international contacts. For interpersonal network size, we asked how the academic's amount of international contacts increased or decreased. In both cases (strength and size), contacts could be friends, colleagues, supervisors, and industrial, academic, or governmental.

\section{Dependent Construct}

Prior studies have measured knowledge gains through simple mobility rates, i.e. inflows and outflows of academics. We agree with the view of Cañibano et al. (2011) that this approximation is rather inadequate as this measure does not actually capture knowledge gained. We therefore capture entrepreneurial knowledge through a separate construct. We asked respondents to indicate how their international experiences helped/contributed to different entrepreneurial knowledge components, a set-up similar to that of other scholars (e.g. Fernández-Pérez et al. 2015; Levin and Cross 2004). These components are: knowledge on how to start/run a viable business, how to identify new business opportunities, certain technologies or products, production of products, offering services, customer needs, and funding or financials. They reflect the four entrepreneurial knowledge categories identified earlier in this paper. For analysis, we transformed the items questioning the different entrepreneurial knowledge components into a count variable, which allows us to assess the degree to which someone received entrepreneurial knowledge. Based on prior research (e.g. Mannucci and Yong 2018), we adhere to the argument that the use of a count variable is more precise than distinguishing between the importance of separate entrepreneurial knowledge components. This approach is also consistent with the theoretical build-up, i.e. looking at entrepreneurial knowledge as a compound construct of heterogeneous knowledge components and with the view that international experiences, bringing along knowledge components, can be considered a cumulative phenomenon 
Table 2 Research sample characteristics

\begin{tabular}{lc}
\hline Characteristics & Percentage \\
\hline Gender & \\
Female & 31.3 \\
Male & 68.7 \\
Research area & \\
Arts \& humanities & 7.5 \\
Life sciences \& biomedicine & 19.9 \\
Physical sciences & 26.0 \\
Social sciences & 21.4 \\
Technology & 23.1 \\
Academic position & \\
Professor & 74.7 \\
PhD student & 8.2 \\
Bachelor or master student & 7.8 \\
Teaching staff & 6.8 \\
Administrative staff & 0.7 \\
Management & 1.8 \\
\hline
\end{tabular}

$\mathrm{n}=281$

(Cañibano et al. 2008). Methodologically, the use of a count variable, with equidistant data points, as a dependent construct in PLS-SEM is supported (Hair et al. 2017).

\section{Control Constructs}

Next to the measurement constructs, we captured controls. For each type of experience, we asked whether the purpose behind the experience was mainly educational, scientific and/or commercial. One might say, for example, that travels with commercial ends produce entrepreneurial knowledge by default. For demographic controls, age and gender were used as single-indicator controls. University support and encouragement towards entrepreneurial endeavors was captured through two Likert-scale items (one on support and one on encouragement). To control for the presence of prior entrepreneurial knowledge, we captured if the academic created a company or knows someone in his/ her close environment who did (binary). We also captured to which country the academic travelled the most over the past five years. Since this question translates into a categorical variable with one category per country, we aggregated the responses to a macro level (North America, Europe, and other) and created single-indicator dummies. In subsequent analysis, we omitted the "other" category as reference category. 


\section{Data Analysis and Results}

\section{Model Preparation}

We conduct an exploratory factor analysis (EFA) to purify the international mobility construct. This reduces the set of indicators used for this construct to a smaller amount which avoids data redundancy and simplifies the model (Janssens et al. 2008). The conditions to conduct the EFA are met as (1) the use of ordinal scales, instead of commonly used interval and ratio scales, is justified since they also generate reliable results, (2) the minimum amount of observations is met (ten times the amount of indicators), and (3) the indicators involved are sufficiently correlated to one another ${ }^{5}$ (Janssens et al. 2008). We conduct the EFA using the principal axis factoring method, which is a popular estimation method providing a parsimonious representation of observed correlations between the indicators (de Winter and Dodou 2012). This method is suitable in our study as we did not have any predefined factor structure in mind and as it allows for subsequent SEM through the use of latent variables. The number of factors to retain was not stated a priori. Based on the combination of several criteria, ${ }^{6}$ three factors are retained and deemed meaningful. ${ }^{7}$ Typically, several activities and experiences are combined during an academic's travel abroad (e.g. a research meeting amongst scholars can take place next to the participation in a conference or teaching at a summer school). Our EFA takes this into account by opting for an oblique rotation method (promax) and allowing for correlation amongst factors after rotation. ${ }^{8} \mathrm{We}$ analyze the resulting rotated component matrix and note that all factor loading values meet the required condition. ${ }^{9}$ We extract factor scores (INT_FAC1, INT_FAC2, and INT_FAC3) and integrate them as indicators of our international temporary mobility construct in our PLS-SEM model for subsequent analysis. An overview of the descriptive statistics of our constructs can be found in the Appendix (electronic supplementary material). These statistics should be interpreted in light of conducting an SEM; not in light of traditional regression analysis. For example, PLS-SEM does not make assumptions about data distribution in its analysis (Hair et al. 2017). The use of non-normal data is even stated as one of the main reasons for its application. The use of the bias-corrected and accelerated bootstrapping routine in PLS-SEM waves this issue to some extent, as it adjusts confidence intervals for skewness (Efron 1987; Hair

\footnotetext{
${ }^{5}$ Our Bartlett's test of sphericity is significant ( $\mathrm{p}$-value $<.001$ ), the Kaiser- Meyer-Olkin measure of sampling adequacy is larger than 0.8 (value of 0.893 ), and values under the diagonal of the anti-image correlation matrix are close to zero.

6 This decision was based on the Kaiser criterion, the evaluation of the scree plot, and parallel analysis (Patil et al. 2008; https://analytics.gonzaga.edu/parallelengine/).

7 Resulting factors can be classified based on knowledge exploration (e.g. internship abroad, study abroad, summer school), exploitation (e.g. contract research visits, consulting visits, use of facilities), and outreach (e.g. participation to conferences or workshop and official academic visits).

8 We request an oblique rotation with a desired number of factors and investigated the resulting factor correlation matrix. All correlations exceed the required 0.32 threshold and warrant the choice for the oblique rotation method.

${ }^{9}$ In case of $250+$ observations, factor loadings should be greater than 0.35 .
} 
et al. 2019). However, in order to obtain reliable results, SEM requires other criteria to be fulfilled. We discuss these next, through the development of the measurement and structural model.

\section{Measurement Model}

We use a measurement model to evaluate the relationships between indicator and their corresponding construct (Hair et al. 2014). Our model uses reflective indicators which represent all possible items within the conceptual domain of the construct (Diamantopoulos and Winklhofer 2001). As a result, causality flows from the construct to the items (Wong 2013). Items can be used interchangeably and can be omitted without losing the meaning of the construct (Hair et al. 2014).

We run the PLS-SEM algorithm taking into account suggested convergence and iteration criteria. ${ }^{10} \mathrm{~A}$ first step in analyzing a reflective measurement model is to evaluate the reliability and validity of the construct measures (Hair et al. 2014). The evaluation of reliability consists of checking indicator reliability and internal consistency reliability. Tables 3 and 4 show that both the outer loadings of the construct items and the composite reliability values meet the commonly used 0.70 or higher threshold (Wong 2013; Hair et al. 2014). Our construct items are sufficiently distinct and reliable.

We assess validity through convergent validity and discriminant validity (Hair et al. 2014). Support for convergent validity is provided when each construct's average variance extracted (AVE) is 0.50 or higher, which would mean that the constructs explain more than half of the variance of the items (Bagozzi and Yi 1988). This is the case for our constructs (see Table 4). Discriminant validity represents the extent to which constructs are empirically different from each other. While previously assessed through the Fornell and Larcker (1981) criterion, ${ }^{11}$ Henseler et al. (2015) show that this approach does not reliably detect the lack of discriminant validity in common research situations. They suggest the use of the heterotrait-monotrait ratio of correlations (HTMT), which is based on the multitrait-multimethod matrix. As our HTMT values are below 0.90, discriminant validity is established (Table 4).

\section{Structural Model and Results}

A structural model displays the relationships between the constructs being evaluated (Hair et al. 2014). Once reliability and validity of the measurement model is established, we take several steps to evaluate the hypothesized relationships between constructs. First, we test the structural model of potential collinearity and common

\footnotetext{
10 Ringle et al. (2015) suggest a maximum number of iterations of 300 . If the data cannot converge in less than 300 iterations, it should be considered abnormal (e.g. sample size too small, outliers, identical values...) (Wong 2013).

11 This criterion suggests that the square root of construct AVE values can be used to establish discriminant validity, if this value is larger than other correlation values among the constructs (Wong 2013).
} 
method bias issues. The collinearity assessment is based on variance inflation factors (VIF) laying between 0.2 and 5. To assure no contamination by common method bias, VIF values should additionally be below 3.3 (Kock 2015). Table 3 shows that these conditions are satisfied; our structural model is free of collinearity and common method bias.

Instead of using traditional goodness-of-fit indexes, the assessment of the structural model is based on its ability to predict the endogenous constructs (Henseler and Sarstedt 2013). To this end, we analyze the path coefficients, which represent the hypothesized relationships linking the constructs (Hair et al. 2014). Estimates are shown in Table 5. These estimates are standardized on a range from -1 to +1 , with coefficients closer to +1 representing strong positive relationships and coefficients closer to -1 indicating strong negative relationships. A bootstrapping procedure $^{12}$ allows to obtain standard errors to test for significance (Wong 2013). The results of this procedure are shown in Table 5 and Fig. 2.

We find that the direct effect of international academic mobility on entrepreneurial knowledge is insignificant ( $\mathrm{p}$-value of 0.591). We reject Hypothesis 1: exposure alone to international experiences does not significantly influence the academic's entrepreneurial knowledge. Looking at the indirect mediated effect through the academic's interpersonal social network, we find that one's network size fully mediates the relationship between international mobility and entrepreneurial knowledge. We thus accept Hypothesis $2 \mathrm{~b}$ (p-value of 0.065 ) but reject $\mathrm{H} 2 \mathrm{a}$ (p-value of 0.973 ). For completeness, coefficients of determination $\left(\mathrm{R}^{2}\right)$ are shown in Fig. 3 as well. However, we should note that the $\mathrm{R}^{2}$ value of EK should be interpreted cautiously since count variables typically display low levels of explanatory power.

\section{Hierarchical Component Model}

Arguably, our social network strength and size constructs can be operationalized on a high level of abstraction (Hair et al. 2014). This level of abstraction makes sense from a theoretical perspective since strength and size form relational and structural properties of one's social network (Phelps et al. 2012). We create a single multidimensional higher-order construct on interpersonal social network $(\mathrm{SN})$. This reduces our model's complexity and averts confounding effects in multidimensional model structures, like multicollinearity. Since, theoretically, our SN construct is of formative nature, i.e. is formed by the strength and size properties, our hierarchical component model constitutes a reflective-formative Type II model (Becker et al. 2012).

Different methods are used to construct and evaluate a hierarchical component model (Sarstedt et al. 2019). We perform the disjoint two-stage approach (DTSA) ${ }^{13}$ (Becker et al. 2012), since our social network construct (SN) also operates as an

\footnotetext{
12 The number of bootstrap samples was set on 5000 as recommended by Hair et al. (2011). We set the amount of results to complete bootstrapping and the confidence interval method to the default biascorrected and accelerated bootstrap.

13 The DTSA first estimates the latent variable score of the lower-order constructs and then uses these as manifest variables for the higher-order construct in the second stage (Sarstedt et al. 2019).
} 
Table 3 Indicators' outer loadings and variance inflation factors

\begin{tabular}{|c|c|c|c|c|c|}
\hline & \multicolumn{4}{|c|}{ Outer loadings } & \multirow[t]{2}{*}{ VIF } \\
\hline & EK & STRENGTH & INT & SIZE & \\
\hline INT_FAC1 & & & 0.836 & & 1.839 \\
\hline INT_FAC2 & & & 0.912 & & 2.606 \\
\hline INT_FAC3 & & & 0.846 & & 1.909 \\
\hline EK & 1.000 & & & & 1.000 \\
\hline FREQ_1 & & 0.717 & & & 2.113 \\
\hline FREQ_2 & & 0.824 & & & 2.819 \\
\hline FREQ_3 & & 0.755 & & & 1.985 \\
\hline FREQ_4 & & 0.721 & & & 2.017 \\
\hline FREQ_5 & & 0.738 & & & 1.571 \\
\hline FREQ_6 & & 0.703 & & & 1.950 \\
\hline SIZE_1 & & & & 0.865 & 3.003 \\
\hline SIZE_2 & & & & 0.859 & 2.950 \\
\hline SIZE_3 & & & & 0.732 & 1.703 \\
\hline SIZE_4 & & & & 0.775 & 1.901 \\
\hline SIZE_5 & & & & 0.795 & 2.113 \\
\hline SIZE_6 & & & & 0.715 & 1.789 \\
\hline
\end{tabular}

INT_FAC(1 - 3) represent the indicators of the international mobility construct (INT). "FAC" notes that these indicators result from an EFA. EK represents the entrepreneurial knowledge indicator and construct (one-on-one relation). FREQ(1-6) represent the indicators of the interpersonal network strength construct (STRENGTH) indicators. "FREQ" refers to the operationalization through measuring the frequency of the interactions. SIZE(1-6) represent the indicators of the interpersonal network size construct (SIZE) indicators

Table 4 Constructs' reliability, average variance extracted, and HTMT assessment

\begin{tabular}{lllllll}
\hline & $\begin{array}{l}\text { Composite } \\
\text { reliability }\end{array}$ & AVE values & \multicolumn{2}{l}{ HTMT assessment } \\
\cline { 4 - 7 } & & & EK & STRENGTH & INT & SIZE \\
\hline EK & 1.000 & 1.000 & - & - & - & - \\
STRENGTH & 0.881 & 0.554 & 0.127 & - & - & - \\
INT & 0.899 & 0.749 & 0.084 & 0.574 & - & - \\
SIZE & 0.910 & 0.627 & 0.135 & 0.597 & 0.413 & - \\
\hline
\end{tabular}

endogenous construct in our mediation model. Particular to this approach is that latent variable scores resulting from the prior analysis are saved for the STRENGTH and SIZE constructs and included in the subsequent hierarchical component model as indicators (LV_STRENGTH and LV_SIZE) of the aggregated SN construct. Estimation of the DTSA demands a Mode B - instead of a Mode A - indicator weighting 
Table 5 Path coefficients' estimates and significance tests

\begin{tabular}{llllll}
\hline in)direct effects & Path coeff. & P-values & Sign. & Hypothesis & Outcome \\
\hline INT -> EK & -0.033 & 0.591 & - & H1 & Rejected \\
INT -> STRENGTH & 0.498 & 0.000 & $* * *$ & - & - \\
INT -> SIZE & 0.354 & 0.000 & $* * *$ & - & - \\
STRENGTH -> EK & 0.002 & 0.973 & - & - & - \\
SIZE -> EK & 0.140 & 0.047 & $* *$ & - & - \\
INT -> STRENGTH -> EK & 0.001 & 0.973 & - & H2a & Rejected \\
INT -> SIZE -> EK & 0.050 & 0.065 & $*$ & H2b & Accepted \\
\hline
\end{tabular}

Significance at $99 \%$ confidence (***), $95 \%$ confidence $(* *), 90 \%$ confidence $(*)$; not significant/ applicable $(-)$

mode $^{14}$ (Sarstedt et al. 2019). This choice relates to the formative character of the relationship between our higher-order construct ( $\mathrm{SN}$ ) and its two properties.

Assessment of the DTSA structural model happens on the grounds of the stage two results (Sarstedt et al. 2019). We find that the measurement model is not negatively affected by collinearity (VIF value of LV_STRENGTH and LV_SIZE is 1.380 ). Both indicators significantly affect the $\mathrm{SN}$ construct (p-values $<0.05$ ), but the influence of LV_STRENGTH on the construct is larger than that of the LV SIZE indicator. Estimates and results of path coefficients are shown in Table 6 and Fig. 3.

In our aggregated hierarchical component model, we find that the mediation effect of one's social network in the relationship between international mobility and entrepreneurial knowledge turns insignificant ( $\mathrm{p}$-value of 0.137). The same happens for the direct effect of social network on entrepreneurial knowledge (p-value of 0.130). This result is explained by the (slightly higher) importance of the strength property (compared to the size property) forming the social network aggregated construct. This shows that, although the strength property is relevant and meaningful in explaining an aggregated social network construct, it negatively influences the relationship between international mobility and entrepreneurial knowledge.

\section{Control Variables}

We test whether the addition of control variables has an effect on observed relationships and constitute alternative explanations to our model (Spector and Brannick 2011). First, our demographic controls, age and gender, did not affect our model significantly. Second, the model may be affected by the amount of entrepreneurial support or encouragement that the academic perceives by his/her home institution.

\footnotetext{
14 In a Mode A, bivariate correlations between each indicator and the construct determine the indicator weights used to compute latent variable scores, while Mode B computes the weights through regression of the constructs on associated indicators (Sarstedt et al. 2019).
} 


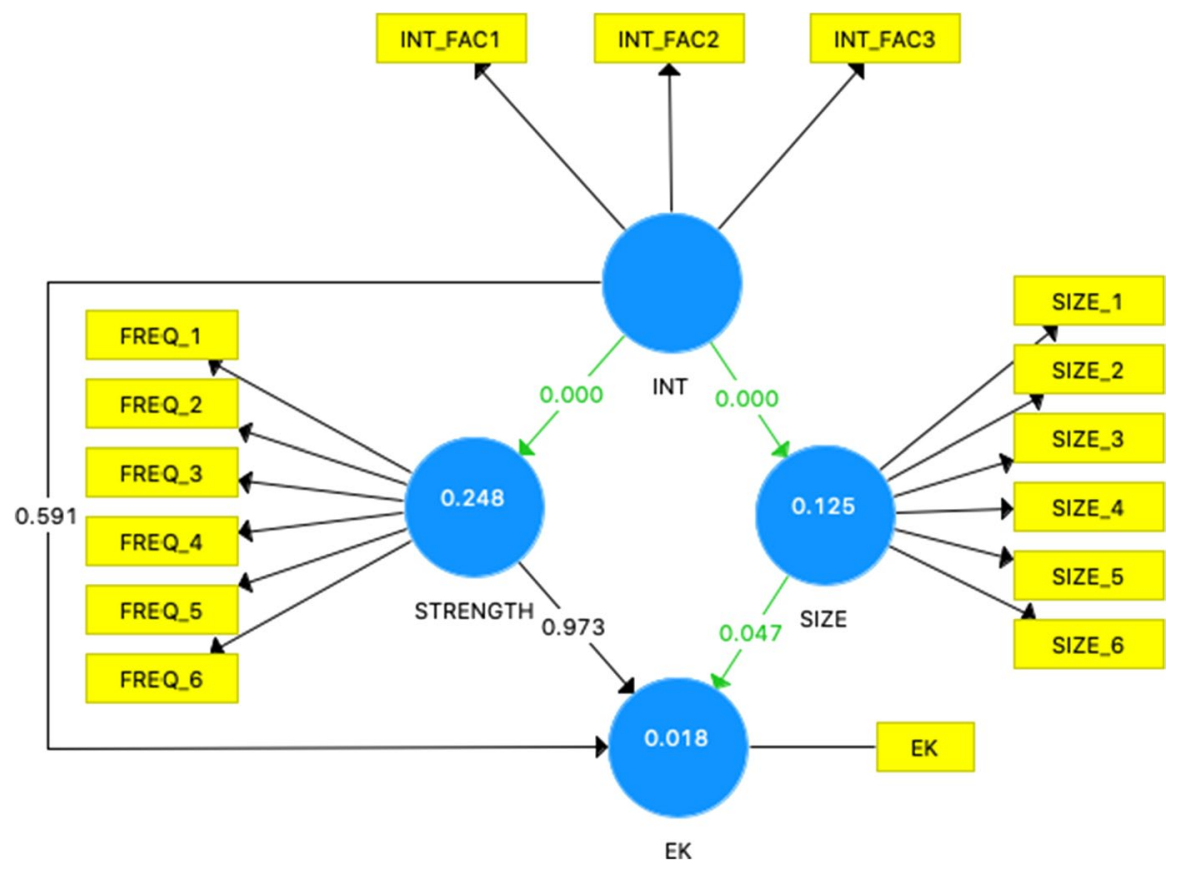

Fig. 2 Visualization of p-values (values on arrows) and significant relationships (green arrows) in our model

Indeed, university support has a positive effect on entrepreneurial knowledge (p-value of 0.001). In addition, the indirect mediation effect through one's social network size turns insignificant. Third, we control for the amount of prior entrepreneurial knowledge an academic might possess. While having started a company or knowing someone who did has a significant effect on entrepreneurial knowledge, the indirect mediation effect through one's social network size remains significant at the $90 \%$ confidence interval ( $\mathrm{p}$-value of 0.082 ). Last, we check if one's entrepreneurial knowledge is affected by the dominant travel destination of the respondent. We find a significant effect for academics who travelled to North America (p-value of 0.000), while the effect for academics who mainly travelled to Europe was insignificant (p-value of 0.111 ). In both cases, the indirect mediation effect through one's social network size remains significant at the $90 \%$ confidence interval (p-value of 0.088 ). We summarize these findings in Table 7.

Additional to these controls, we investigate the reasons for academics to be internationally mobile in the first place. One might argue that academics who travel abroad with commercial intentions in mind, are more prone to receive entrepreneurial knowledge than peers who do not show similar intentions. Our data shows that commercial aims were only reported by $3.7 \%$ of the academics, which is an average over all types of international experiences. This low percentage waves the argument that our model is biased by academics actively searching for entrepreneurial knowledge. 


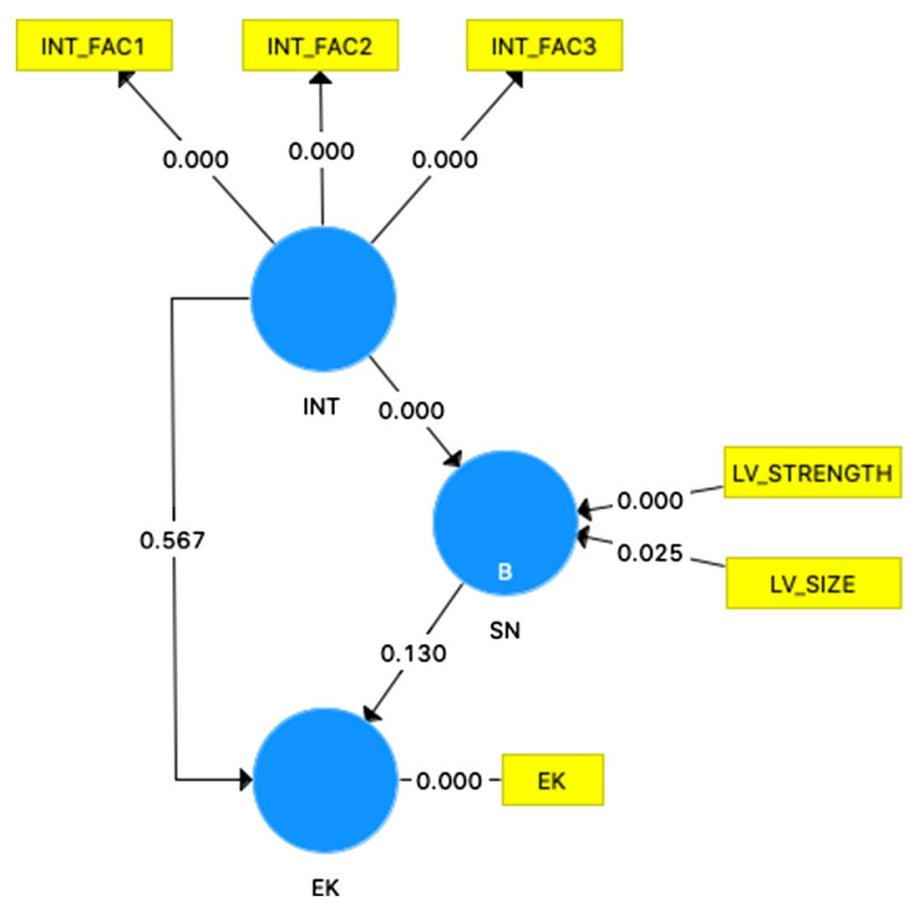

Fig. 3 Disjoint two-stage approach model (p-values on arrows)

\section{Discussion of Results}

We find that the size of the academic's interpersonal social network fully mediates the relationship between international mobility and entrepreneurial knowledge. This finding is in line with our premise that the academic's social network plays a crucial role in the transfer of knowledge while being abroad. This finding relates to studies pointing to social capital and network formation as ingredient for the accumulation of internationally gained resources (e.g. Bauder 2020; Drori et al. 2009; Hoch 1987). With respect to the kind of entrepreneurial knowledge received, we observe that Chinese academics mostly report to have gained knowledge on how to identify opportunities (23.8\%) and on how to start a viable business (21\%), followed by knowledge on offering services (16.7\%), on customer needs (15.7\%), production $(12.1 \%)$, and finances $(8.2 \%)$. Chinese academics mostly gain market and organizational knowledge and to a lesser extent product and financial knowledge (Shane 2002; Widding 2005).

Mere exposure to international experiences, i.e. a direct relationship, does not influence the academic's entrepreneurial knowledge. We find this slightly surprising, since one could, for example, argue that attending lectures or presentations at conferences directly provides knowledge relating to some of the entrepreneurial knowledge components and thus extend one's entrepreneurial knowledge. However, our model does not take into account specific or different country and/or institutional aspects that can influence one's entrepreneurial knowledge, even without frequent 
Table 6 Path coefficients' estimates and significance tests of hierarchical component model

\begin{tabular}{llll}
\hline in)direct effects & Path coefficients & P-values & Sign. \\
\hline INT -> EK & -0.036 & 0.567 & - \\
INT -> SN & 0.510 & 0.000 & $* * *$ \\
SN -> EK & 0.105 & 0.130 & - \\
INT -> SN -> EK & 0.053 & 0.137 & - \\
\hline
\end{tabular}

Significance at $99 \%$ confidence $(* * *), 95 \%$ confidence $(* *), 90 \%$ confidence $(*)$; not significant/ applicable (-)

or in-depth interactions with an international network (Busenitz et al. 2000). In particular to the international context, an academic's cultural background may limit or shape the amount of knowledge captured, how that knowledge is perceived (e.g. in terms of trustworthiness), and how important it becomes in one's knowledge base (Dietz et al. 2010).

Our analysis also points to the particular importance of the structural size property over the relational strength property in the academic's interpersonal social network. Thus, in order to receive entrepreneurial knowledge through international temporary mobility, the academic should focus on extending and broadening one's international network instead of deepening relations within one's existing network. This means that it is especially the new international connections that extend the academic's knowledge base with heterogeneous entrepreneurial knowledge components (van Rijnsoever et al. 2008; Hoang and Antoncic 2003; Rasmussen et al. 2015) and not the existing connections providing other components through additional interactions. While prior research also notes that frequent interactions with informal contacts may provide heterogeneous knowledge, our study does not show similar result. However, we find this not very surprising due to the international context. Drori et al. (2009), for example, argue that while abroad people avoid the closer interpersonal contacts as these could constrain their access to novelty and heterogeneity in resources. The authors give the example of a Chinese transnational entrepreneur in North Ireland that saw no advantage to network with the Chinese community in Belfast. Although their study focuses on a priori entrepreneurs, the same reasoning applies in our study: academics, while abroad engage with new contacts to get the most out of their travels in terms of novelty and non-redundancy of knowledge received.

The mediation effect of social network size in the relation between international mobility and entrepreneurial knowledge only turns insignificant when university support is controlled for in our model. University support and encouragement towards entrepreneurship plays a crucial role in the enlargement of one's entrepreneurial knowledge. Such support seems to outweigh the need for a broad international network. We believe that this is the result of entrepreneurship-related staff and courses being accessible and leveraged upon by academics that find themselves in so-called entrepreneurial universities, which translates into the availability of different entrepreneurial knowledge components (Wu 2010). Our results also point to the importance of the social network size property in receiving entrepreneurial knowledge even when academics already possess a certain amount of prior entrepreneurial 
Table 7 Overview of significance tests on control variables

\begin{tabular}{lll}
\hline Control variables (CV) & CV -> EK (Sign.) & $\begin{array}{l}\text { IM -> SIZE } \\
->\text { EK } \\
\text { (Sign.) }\end{array}$ \\
\hline Demographics & - & $*$ \\
University support & $* * *$ & - \\
Prior knowledge & $* * *$ & $*$ \\
Dom. Destination: NA & $* * *$ & $*$ \\
Dom. Destination: EUR & - & $*$ \\
\hline
\end{tabular}

Significance at $99 \%$ confidence (***), $95 \%$ confidence $(* *), 90 \%$ confidence $(*)$; not significant/ applicable (-)

knowledge, e.g. through having started a company or knowing someone who did. This result supports the creation and establishment of international networks outside one's existing research group, university, or even region, i.e. so-called cosmopolitan networks (Bozeman and Corley 2004; Hayter 2016), as such networks may provide additional knowledge and ideas complementing individuals' prior entrepreneurial knowledge bases, which typically hold localized knowledge.

\section{Conclusion and Limitations}

This paper studies the relationship between international temporary academic mobility and entrepreneurial knowledge. In particular, it investigates the role of interpersonal social networks, in terms of their size and strength property, in this relationship. We do not find a direct relationship between international mobility and entrepreneurial knowledge. Without interactions abroad, i.e. when isolating oneself, academics will not enlarge their entrepreneurial knowledge base. However, in terms of the indirect relationship through one's social network, we find that the size of the academic's social network fully mediates the relationship between international mobility and entrepreneurial knowledge. New international contacts extend the academic's knowledge base with heterogeneous entrepreneurial knowledge components. Our research provides support to the idea that academics reap benefits from their internationalization efforts, adhering to the brain gain discourse. Previous studies have reported positive effects of international mobility on (scientific) productivity, career development, and knowledge transfer activities (e.g. Veugelers and Van Bouwel 2015; Edler et al. 2011). Our research now complements these studies with the insight that academics, while being abroad, increase their entrepreneurial knowledge through the expansion of their interpersonal network.

Our study has several limitations which constitute interesting pathways for further research. The first limitation concerns our data and methodology. While PLS-SEM is suitable to study cause-effect relationships through a mediating construct (Hair et al. 2017), we do not argue causality in our study. To build a convincing case for a causal relationship, we should demonstrate a temporal sequence 
by which the presumed cause precedes the presumed effect. Our data is limited towards such demonstration. Our data also builds upon a sample that represents only $1.2 \%$ of the studied population. Although we compare our sample to related research, this limits the representativeness and generalizability of our study. As path analysis and SEM are getting more popular, the use of controls in structural models, and especially in mediated models, needs further attention (Atinc et al. 2012). Second, we operationalized our model with a focus on the importance of heterogeneity in the entrepreneurial knowledge base. While this approach is supported by existing literature, some scholars (e.g. Miralles et al. 2016) point to the particular importance of combining heterogeneous and homogenous knowledge components to form one's entrepreneurial knowledge. While we support this argument, we argue that coordination and recombination of homogenous and heterogeneous knowledge parts is crucial to the identification of entrepreneurial opportunities, which constitutes a first step of the entrepreneurial process (D'Este et al. 2012). Our study is limited to study the perceived receipt of entrepreneurial knowledge (Levin and Cross 2004) and does not make statements on the potential subsequent engagement of the academic in the entrepreneurial process. In that regard, we also limit ourselves to knowledge as a key resource and discard other individual level resources and capabilities (e.g. networking capability). Third, since Chinese academics tend to travel mostly to the West for international temporary mobility experiences - which shows in our data - our findings may be limited to a setting in which academics from an emerging country travel to developed countries (Wright et al. 2005). The inverse setting may constitute an interesting path for future research. We also question why academics travel to certain destinations in the first place and if/how this choice relates to the (entrepreneurial) knowledge acquired. Last, our study does not take into account any domestic academic mobility or the complementary or substitute role domestic networks could play in our model. For example, due to proximity aspects, we would expect the role of frequent interactions to be more prevalent in a domestic academic mobility setting. Also, the existing domestic interpersonal networks may play a crucial role in the return of the academic to the home country (Bauder 2020; Baruffaldi and Landoni 2012).

\section{Declarations}

Conflict of interest The authors declare that they have no conflict of interest.

Open Access This article is licensed under a Creative Commons Attribution 4.0 International License, which permits use, sharing, adaptation, distribution and reproduction in any medium or format, as long as you give appropriate credit to the original author(s) and the source, provide a link to the Creative Commons licence, and indicate if changes were made. The images or other third party material in this article are included in the article's Creative Commons licence, unless indicated otherwise in a credit line to the material. If material is not included in the article's Creative Commons licence and your intended use is not permitted by statutory regulation or exceeds the permitted use, you will need to obtain permission directly from the copyright holder. To view a copy of this licence, visit http://creativecommons.org/licen ses/by/4.0/. 


\section{References}

Adams, Walter. 1968. Introduction. In The Brain Drain. New York: Macmillan.

Alvarez, Sharon A., and Lowell W. Busenitz. 2001. The entrepreneurship of resource-based theory. Journal of Management 27: 755-775.

Atinc, Guclu, Marcia J. Simmering, and Mark J. Kroll. 2012. Control variable use and reporting in macro and micro management research. Organizational Research Methods 15: 57-74.

Audretsch, David B., Erik E. Lehmann, and Stefano Paleari. 2015. Academic policy and entrepreneurship: a European perspective. The Journal of Technology Transfer 40: 363-368.

Bagozzi, Richard P., and Youjae Yi. 1988. On the evaluation of structural equation models. Journal of the Academy of Marketing Science 16: 74-94.

Baron, Reuben M., and David A. Kenny. 1986. The moderator-mediator variable distinction in social psychological research: conceptual, strategic, and statistical considerations. Journal of Personality and Social Psychology 51: 1173-1182.

Baruffaldi, Stefano H., and Paolo Landoni. 2012. Return mobility and scientific productivity of researchers working abroad: the role of home country linkages. Research Policy 41: 1655-1665.

Bauder, Harald. 2020. International mobility and social capital in the academic field. Minerva 58(3): 367-387.

Becker, Jan-Michael., Kristina Klein, and Martin Wetzels. 2012. Hierarchical latent variable models in PLS-SEM: guidelines for using reflective-formative type models. Long Range Planning 45: 359-394.

Bercovitz, Janet, and Maryann Feldman. 2008. Academic entrepreneurs: organizational change at the individual level. Organization Science 19: 69-89.

Bienkowska, Dzamila, and Magnus Klofsten. 2012. Creating entrepreneurial networks: academic entrepreneurship, mobility and collaboration during PhD education. Higher Education 64: 207-222.

Bienkowska, Dzamila, Mats Lundmark, and Anders Malmberg. 2011. Brain circulation and flexible adjustment: labour mobility as a cluster advantage. Geografiska Annaler: Series B, Human Geography 93: 21-39.

Bozeman, Barry, and Elizabeth Corley. 2004. Scientists' collaboration strategies: implications for scientific and technical human capital. Research Policy 33: 599-616.

Brass, Daniel J. 1992. Power in organizations: a social network perspective. Politics and Society 4: 295-323.

Buckley, Peter J., Jeremy Clegg, and Hui Tan. 2006. Cultural awareness in knowledge transfer to ChinaThe role of guanxi and mianzi. Journal of World Business 41: 275-288.

Busenitz, Lowell W., Carolina Gomez, and Jennifer W. Spencer. 2000. Country institutional profiles: unlocking entrepreneurial phenomena. Academy of Management Journal 43: 994-1004.

Cañibano, Carolina, Javier F. Otamendi, and Francisco Solís. 2011. International temporary mobility of researchers: a cross-discipline study. Scientometrics 89: 653-675.

Cañibano, Carolina, Javier F. Otamendi, and Inés. Andújar. 2008. Measuring and assessing researcher mobility from CV analysis: the case of the Ramón y Cajal programme in Spain. Research Evaluation 17: 17-31.

Casson, Mark, and Marina D. Giusta. 2007. Entrepreneurship and social capital: analysing the impact of social networks on entrepreneurial activity from a rational action perspective. International Small Business Journal 25: 220-244.

Cervantes, Mario, and Dominique Guellec. 2002. The brain drain: old myths, new realities. The OECD Observer 230: 40-42.

Cetin, Delik, Ana Fernandez-Zubieta, and Fulvio Mulatero. 2016. Formal and informal social capital as determinants of male and female entrepreneurship in Europe. Cankiri Karatekin University Journal of the Faculty of Economics and Administrative Sciences 6: 723-748.

Chou, Shih-Wei. 2005. Knowledge creation: absorptive capacity, organizational mechanisms, and knowledge storage/retrieval capabilities. Journal of Information Science 31: 453-465.

Cohen, Jacob. 1990. Things I have learned (so far). American Psychologist 45: 1304-1312.

Cumming, Geoff, and Sue Finch. 2005. Inference by eye: confidence intervals and how to read pictures of data. American Psychologist 60: 170-180.

D’Este, Pablo, Surya Mahdi, Andy Neely, and Francesco Rentocchini. 2012. Inventors and entrepreneurs in academia: what types of skills and experience matter? Technovation 32: 293-303. 
Davenport, Sally. 2004. Panic and panacea: brain drain and science and technology human capital policy. Research Policy 33: 617-630.

Davidsson, Per, and Benson Honig. 2003. The role of social and human capital among nascent entrepreneurs. Journal of Business Venturing 18: 301-331.

Davison, Robert M., Carol X.J.. Ou, and Mari G. Martinsons. 2018. Interpersonal knowledge exchange in China: the impact of guanxi and social media. Information \& Management 55: 224-234.

De Moortel, Kevin, and Thomas Crispeels. 2018. International university-university technology transfer: strategic management framework. Technological Forecasting and Social Change 135: 145-155.

de Winter, Joost, and Dimitra Dodou. 2012. Factor recovery by principal axis factoring and maximum likelihood factor analysis as a function of factor pattern and sample size. Journal of Applied Statistics 39: 695-710.

Diamantopoulos, Adamantios, and Heidi M. Winklhofer. 2001. Index construction with formative indicators: an alternative to scale development. Journal of Marketing Research 38: 269-277.

Dietz, Graham, Nicole Gillespie, and Georgie T. Chao. 2010. Unravelling the complexities of trust and culture. In Organizational Trust: A Cultural Perspective, eds. Mark N.K. Saunders, Denise Skinner, Graham Dietz, Nicole Gillespie, and Roy J. Lewicki, 3-41. New York: Cambridge University Press.

Drori, Israel, Benson Honig, and Mike Wright. 2009. Transnational entrepreneurship: an emergent field of study. Entrepreneurship Theory and Practice 33: 1001-1022.

Eckhardt, Jonathan T., and Scott A. Shane. 2003. Opportunities and entrepreneurship. Journal of Management 29: 333-349.

Edler, Jakob, Heide Fier, and Christoph Grimpe. 2011. International scientist mobility and the locus of knowledge and technology transfer. Research Policy 40: 791-805.

Efron, Bradley. 1987. Better bootstrap confidence intervals. Journal of the American Statistical Association 82: 171-185.

Fornell, Claes, and David F. Larcker. 1981. Evaluating structural equation models with unobservable variables and measurement error. Journal of Marketing Research 18: 39-50.

Fuentes-Fuentes, Maria del Mar, Matilde R. Arroyo, Ana M. Bojica, and Virginia F. Pérez. 2010. Prior knowledge and social networks in the exploitation of entrepreneurial opportunities. International Entrepreneurship and Management Journal 6: 481-501.

Gibson, John, and David McKenzie. 2014. Scientific mobility and knowledge networks in high emigration countries: evidence from the Pacific. Research Policy 43: 1486-1495.

Goethner, Maximilian, Martin Obschonka, Rainer K. Silbereisen, and Uwe Cantner. 2012. Scientists' transition to academic entrepreneurship: economic and psychological determinants. Journal of Economic Psychology 33: 628-641.

Granovetter, Mark S. 1973. The strength of weak ties. American Journal of Sociology 78: 1360-1380.

Hair, Joe F., Christian M. Ringle, and Marko Sarstedt. 2011. PLS-SEM: indeed a silver bullet. Journal of Marketing Theory and Practice 19: 139-151.

Hair, Joe F., Marko Sarstedt, Lucas Hopkins, and Volker G. Kuppelwieser. 2014. Partial least squares structural equation modeling (PLS-SEM): an emerging tool in business research. European Business Review 26: 106-121.

Hair, Joseph F., Jeffrey J. Risher, Marko Sarstedt, and Christian M. Ringle. 2019. When to use and how to report the results of PLS-SEM. European Business Review 31: 2-24.

Hair, Joseph F., Tomas M. Hult, Christian M. Ringle, and Marko Sarstedt. 2017. A Primer on Partial Least Squares Structural Equation Modeling (PLS-SEM). SAGE Publications, Inc.

Hayter, Christopher S. 2016. Constraining entrepreneurial development: a knowledge-based view of social networks among academic entrepreneurs. Research Policy 45: 475-490.

Henseler, Jörg, and Marko Sarstedt. 2013. Goodness-of-fit indices for partial least squares path modeling. Computational Statistics 28: 565-580.

Henseler, Jörg, Christian M. Ringle, and Marko Sarstedt. 2015. A new criterion for assessing discriminant validity in variance-based structural equation modeling. Journal of the Academy of Marketing Science 43: 115-135.

Hoang, Ha, and Bostjan Antoncic. 2003. Network-based research in entrepreneurship: a critical review. Journal of Business Venturing 18: 165-187.

Hoch, Paul K. 1987. Migration and the generation of new scientific ideas. Minerva 25: 209-237.

Honig, Benson. 2004. Entrepreneurship education: Toward a model of contingency-based business planning. Academy of Management Learning and Education 5: 258-273. 
Hoyle, Rick H. 1995. Structural Equation Modeling: Concepts, Issues, and Applications. SAGE Publications, Inc.

Hunt, Jennifer, and Marjolaine Gauthier-Loiselle. 2010. How much does immigration boost innovation? American Economic Journal: Macroeconomics 2: 31-56.

Jacobs, Jane. 1969. The Economy of Cities. New York: Random House.

Janssens, Wim, Katrien Wijnen, Patrick De Pelsmacker, and Patrick Van Kenhove. 2008. Marketing research with SPSS. Harlow: Pearson Education.

Jonkers, Koen, and Laura Cruz-Castro. 2013. Research upon return: the effect of international mobility on scientific ties, production and impact. Research Policy 42: 1366-1377.

Jonkers, Koen, and Robert Tijssen. 2008. Chinese researchers returning home: impacts of international mobility on research collaboration and scientific productivity. Scientometrics 77: 309-333.

Kock, Ned. 2015. Common method bias in PLS-SEM: a full collinearity assessment approach. International Journal of e-Collaboration (ijec) 11: 1-10.

Krabel, Stefan, Donald S. Siegel, and Viktor Slavtchev. 2012. The internationalization of science and its influence on academic entrepreneurship. Journal of Technology Transfer 37: 192-212.

Levin, Daniel Z., and Rob Cross. 2004. The strength of weak ties you can trust: the mediating role of trust in effective knowledge transfer. Management Science 50: 1477-1490.

Maggioni, Mario A., and Teodora E. Uberti. 2009. Knowledge networks across Europe: which distance matters? Annals of Regional Science 43: 691-720.

Mannucci, Pier V., and Kevyn Yong. 2018. The differential impact of knowledge depth and knowledge breadth on creativity over individual careers. Academy of Management Journal 61: 1741-1763.

McEvily, Bill, and Akbar Zaheer. 1999. Bridging ties: a source of firm heterogeneity in competitive capabilities. Strategic Management Journal 20: 1133-1156.

Mei, Bing, and Gavin T. L. Brown. 2018. Conducting Online Surveys in China. Social Science Computer Review 36: 721-734.

Melkers, Julia, and Agrita Kiopa. 2010. The social capital of global ties in science: the added value of international collaboration. Review of Policy Research 27: 389-414.

Miralles, Francesc, Ferran Giones, and Carla Riverola. 2016. Evaluating the impact of prior experience in entrepreneurial intention. International Entrepreneurship and Management Journal 12: 791-813.

Morhman, Kathryn, Yiqun Geng, and Yingjie Wang. 2011. Faculty Life in China. https://www.researchga te.net/publication/265004900_Faculty_Life_in_China. Accessed 29 March 2021.

Olmos-Peñuela, Julia, Paul Benneworth, and Elena Castro-Martínez. 2015. What stimulates researchers to make their research usable? Towards an 'openness' approach. Minerva 53(4): 381-410.

Orazbayev, Sultan. 2017. International knowledge flows and the administrative barriers to mobility. Research Policy 46: 1655-1665.

Pagani, Regina N., Bruno Ramond, Vander L. Da Silva, Gilberto Zammar, and Joao L. Kovaleski. 2019. Key factors in university-to-university knowledge and technology transfer on international student mobility. Knowledge Management Research \& Practice 18: 1-19.

Patil, Vivek H., Surendra N. Singh, Sanjay Mishra, and Todd D. Donavan. 2008. Efficient theory development and factor retention criteria: abandon the 'eigenvalue greater than one' criterion. Journal of Business Research 61: 162-170.

Pérez, Virginia F., Patricia E. Alonso-Galicia, Lázaro Rodríquez-Ariza, and María del Mar FuentesFuentes. 2015. Professional and personal social networks: a bridge to entrepreneurship for academics? European Management Journal 33: 37-47.

Perkmann, Markus, Valentina Tartari, Maureen McKelvey, Erkko Autio, Anders Broström, Pablo D’Este, Riccardo Fini, et al. 2013. Academic engagement and commercialisation: A review of the literature on university-industry relations. Research Policy 42: 423-442.

Phelps, Cory, Ralph Heidl, and Anu Wadhwa. 2012. Knowledge, networks, and knowledge networks: a review and research agenda. Journal of Management 38: 1115-1166.

Politis, Diamanto. 2008. Does prior start-up experience matter for entrepreneurs' learning? Journal of Small Business and Enterprise Development 15: 472-489.

Pretorius, Marius, Gideon Nieman, and Jurie van Vuuren. 2005. Critical evaluation of two models for entrepreneurial education: an improved model through integration. International Journal of Educational Management 19: 413-427.

Ramasamy, Bala, K.W. Goh, and Matthew C.H. Yeung. 2006. Is guanxi (relationship) a bridge to knowledge transfer? Journal of Business Research 59: 130-139. 
Rasmussen, Einar, Simon Mosey, and Mike Wright. 2015. The transformation of network ties to develop entrepreneurial competencies for university spin-offs. Entrepreneurship and Regional Development 27: 430-457.

Regets, Mark. 2007. Research issues in the international migration of highly skilled workers: a perspective with data from the United States. https://nbn-resolving.org/urn:nbn:de:0168-ssoar-312665. Accessed 20 March 2021.

Ringle, Christian M., Sven Wende, and Jan-Michael Becker. 2015. SmartPLS 3. Bönningstedt: SmartPLS. Retrieved from http://www.smartpls.com.

Rostan, Michele, and Ester A. Höhle. 2014. The International Mobility of Faculty. In The Internationalization of the Academy: Changes, Realities and Prospects, eds. Huang, Futao, Martin Finkelstein, and Michele Rostan, 79-104. Springer.

Sarstedt, Marko, Joseph F. Hair, Jun-Hwa Cheah, Jan-Michael Becker, and Christian M. Ringle. 2019. How to specify, estimate, and validate higher-order constructs in PLS-SEM. Australasian Marketing Journal 27: 197-211.

Scellato, Giuseppe, Chiara Franzoni, and Paula Stephan. 2015. Migrant scientists and international networks. Research Policy 44: 108-120.

Shane, Scott. 2002. Prior knowledge and the discovery of entrepreneurial opportunities. Management Science 47: 205-220.

Shen, Hong. 2008. Progress of the academic profession in mainland China. In The Changing Academic Profession in International Comparative and Quantitative Perspectives, 251-264. Hiroshima: Research Institute for Higher Education Hiroshima University.

Siegel, Donald S., and Mike Wright. 2015. Academic entrepreneurship: time for a rethink? British Journal of Management 26: 582-595.

Spector, Paul E., and Michael T. Brannick. 2011. Methodological urban legends: the misuse of statistical control variables. Organizational Research Methods 14: 287-305.

Stanfield, David A., and Yukiko Shimmi. 2014. Chinese higher education: statistics and trends. In Global Opportunities and Challenges for Higher Education Leaders: Briefs on Key Themes, eds. Rumbley, Laura E., Robin M. Helms, Patti M. Peterson, and Philip G. Altbach, 77-82. SensePublishers.

Stephan, Paula, and Sharon G. Levin. 2001. Exceptional contributions to US science by the foreign-born and foreign-educated. Population Research and Policy Review 20: 59-79.

Teichler, Ulrich. 2015. Academic mobility and migration: what we know and what we do not know. European Review 23: 6-37.

Trippl, Michaela. 2013. Scientific mobility and knowledge transfer at the interregional and intraregional level. Regional Studies 47: 1653-1667.

Urry, John. 2002. Mobility and proximity. Sociology 36: 255-274.

van Rijnsoever, Frank J., Laurens K. Hessels, and Rens L. J. Vandeberg. 2008. A resource-based view on the interactions of university researchers. Research Policy 37: 1255-1266.

Venkataraman, Sankaran. 1997. The distinctive domain of entrepreneurship research. In Advances in Entrepreneurship, Firm Emergence and Growth, eds. Jerome Katz, and Robert Brockhaus, $119-138$.

Veugelers, Reinhilde, and Linda Van Bouwel. 2015. The effects of international mobility on European researchers: comparing intra-EU and U.S. mobility. Research in Higher Education 56: 360-377.

Villanueva-Felez, Africa, Jordi Molas-Gallart, and Alejandro Escribá-Esteve. 2013. Measuring personal networks and their relationship with scientific production. Minerva 51(4): 465-483.

Wadhwa, Vivek, AnnaLee Saxenian, Ben A. Rissing, and G. Gereffi. 2008. Skilled immigration and economic growth. Applied Research in Economic Development 5: 6-14.

Wang, Jue, Rosalie Hooi, Andrew X. Li, and Meng-hsuan Chou. 2019. Collaboration patterns of mobile academics: the impact of international mobility. Science and Public Policy 46: 1-13.

Widding, Lars $\varnothing$. 2005. Building entrepreneurial knowledge reservoirs. Journal of Small Business and Enterprise Development 12: 595-612.

Wold, Herman. 1974. Causal flows with latent variables: partings of ways in the light of NIPALS modelling. European Economic Review 5: 67-86.

Wong, Ken K.-K.. 2013. Partial least squares structural equation modeling (PLS-SEM) techniques using SmartPLS. Marketing Bulletin 24: 1-32.

Wright, Mike, Sarika Pruthi, and Andy Lockett. 2005. International venture capital research: from cross-country comparisons to crossing borders. International Journal of Management Reviews 7: $135-165$. 
Wu, Amery D., and Bruno D. Zumbo. 2008. Understanding and using mediators and moderators. Social Indicators Research 87: 367-392.

Wu, Weiping. 2010. Managing and incentivizing research commercialization in Chinese Universities. The Journal of Technology Transfer 35: 203-224.

Xin, Katherine R., and Jone L. Pearce. 1996. Guanxi: Connections as substitutes for formal institutional support. Academy of Management Journal 39: 1641-1658.

Yasuda, Satoko. 2016. Mobility and academic entrepreneurship: an empirical analysis of Japanese scientists. In University Evolution, Entrepreneurial Activity and Regional Competitiveness, eds. David Audretsch, Erik Lehmann, Michele Meoli, and Vismara Silvio, 27-47. New York: Springer International Publishing.

Publisher's Note Springer Nature remains neutral with regard to jurisdictional claims in published maps and institutional affiliations. 